\title{
INTEGRASI IDEAS FRAMEWORK DAN BRIEF SURVEY DALAM MENGEVALUASI MUSCULOSKELETAL DISORDERS
}

\author{
Muhammad Rafi Wardana, Lina Dianati Fathimahhayati, Theresia Amelia Pawitra \\ Program Studi Teknik Industri Universitas Mulawarman \\ e-mail: rafiwardana12@gmail.com, linadianatif@gmail.com,triciapawitra@gmail.com
}

\begin{abstract}
ABSTRAK
Pabrik Tahu Pak Kasimin merupakan salah satu industri tahu yang memproduksi tahu mentah dan tahu goreng. Pabrik yang berlokasi di Kelurahan Selili Kota Samarinda ini telah beroperasi sejak tahun 30 lalu dengan target produksi perharinya yaitu $150 \mathrm{~kg}$ tahu. Target produksi yang cukup besar ini menimbulkan berbagai keluhan oleh pekerjanya, salah satunya yaitu keluhan musculoskeletal disorders pada saat melakukan proses produksi tahu. Penelitian ini bertujuan untuk memberikan usulan perbaikan terhadap postur kerja pada Pabrik Tahu Pak Kasimin. Metode yang diterapkan pada penelitian ini yaitu IDEAS Framework sebagai kerangka utama penelitian, metode BRIEF Survey untuk mengevaluasi postur kerja, dan kuisioner Nordic Body Map untuk mengidentifikasi keluhan musculoskeletal disorders. Hasil evaluasi yang dilakukan menggunakan BRIEF Survey didapatkan bahwa pada postur kerja aktivitas penyaringan bubur kedelai memiliki skor rata-rata 3 (risiko tinggi) dan penyusunan kayu bakar juga memiliki skor rata-rata 3 (risiko tinggi) sehingga perlunya dilakukan perbaikan pada stasiun kerja tersebut.
\end{abstract}

Kata kunci: BRIEF, IDEAS, MSDs, Pabrik.

\begin{abstract}
Mr. Kasimin's Tofu Factory is one of the tofu industries that produces raw tofu and fried tofu. The factory, located in Selili Village Office, Samarinda City, has been operating since 30 years ago with a daily production target of $150 \mathrm{~kg}$ of tofu. This large production target has caused various complaints by workers, one of which is the complaints of musculoskeletal disorders during the process of tofu production. This study aims to provide suggestions for improvement of work postures at the Mr.Kasimin's Tofu Factory. The methods applied in this study are IDEAS Framework as the main research framework, the BRIEF Survey method for evaluating work postures, and the Nordic Body Map questionnaire to identify complaints of musculoskeletal disorders. The results of evaluations conducted using the BRIEF Survey found that in the work posture filtering activities of soybean porridge had an average score of 3 (high risk) and the preparation of firewood also had an average score of 3 (high risk) so that the need for repairs to the work station
\end{abstract}

Keywords: BRIEF, Factory, IDEAS, MSDs.

\section{PENDAHULUAN}

Berdasarkan hasil Riset Kesehatan Dasar (Riskesdas) pada tahun 2013, menyatakan bahwa prevalensi penyakit sendi bedasarkan hasil diagnosis tenaga kesehatan di Indonesia sebesar 11,9\% dan berdasarkan diagnosis atau gejala sebesar $24,7 \%$. Selain itu berdasarkan hasil survei terhadap prevalensi nyeri punggung bawah karena posisi duduk sebesar 39,7\% dimana, 12,6\% sering menimbulkan keluhan, 1,2\% kadang-kadang menimbulkan keluhan dan 26,9\% jarang menimbulkan keluhan [1].

Keluhan pada musculoskeletal juga dialami oleh beberapa pekerja pabrik dikota Samarinda, salah satunya dirasakan oleh pekerja Pabrik Tahu Pak Kasimin. Pabrik tahu ini berlokasi dijalan Lumba-lumba Kelurahan Selili, Samarinda. Pabrik ini beroperasi setiap harinya selama 12 jam dengan target produksi sebesar $150 \mathrm{~kg}$ tahu per hari. Empat orang pekerja Pabrik Tahu Pak Kasimin merasakan keluhan musculoskeletal berupa cedera otot dan pegal pada persendiaan. Keluhan musculoskeletal tersebut seringkali dirasakan pekerja pada stasiun kerja penyaringan bubur kedelai, stasiun kerja pencetakan tahu dan stasiun kerja penggorengan tahu. Cedera ini pada umumnya disebut sebagai cedera okupasional atau cedera pekerjaan. 
Berdasarkan penelitian yang telah dilakukan sebelumnya, terdapat $20 \%$ penyakit akibat kerja berupa cedera dan terdapat $11 \%$ penyakit akibat kerja berupa pegal pada persendian dalam proses pembuatan tahu [2]. Timbulnya cedera ini diakibatkan aktivitas manual material handling atau pemindahan barang dengan menggunakan tenaga manusia, cedera pada otot ini merupakan salah satu risiko dari postur pekerja yang salah atau beban material yang diangkat terlalu berat.

Istilah ergonomi dikenal dalam bahasa Yunani, dari kata ergos dan nomos yang memiliki arti "kerja" dan "aturan atau kaidah", dari dua kata tersebut secara pengertian bebas sesuai dengan perkembangannya, yakni suatu aturan atau kaidah yang ditaati dalam lingkungan pekerjaan [3]. Ergonomi juga dapat diartikan sebagai disiplin ilmu yang berkaitan dengan pemahaman interaksi di antara manusia dan unsur-unsur lain dari suatu sistem, dan profesi yang menerapkan teori, prinsip, data, dan metode yang dirancang untuk mengoptimalkan kesejahteraan manusia dan sistem keseluruhan kinerja [4].

Musculoskeletal Disorders (MSDs) merupakan cedera atau gangguan pada sistem muskuloskeletal akibat paparan berulang terhadap berbagai bahaya dan/atau faktor risiko dalam sistem muskuloskeletal tempat kerja mencakup semua otot, tulang, tendon, selubung tendon, ligamen, bursa, pembuluh darah, sendi, diskus intervertebralis [5].

Aktivitas MMH (Manual Material Handling) seperti mengangkat beban dengan teknik yang tidak aman dapat menimbulkan dampak buruk bagi pekerja. Salah satu akibat yang ditimbulkan adalah keluhan muskuloskeletal [6].

Material handling dinyatakan sebagai seni dan ilmu yang meliputi penanganan (handling), pemindahan (moving), pengepakan (packaging), penyimpanan (storing) dan pengawasan (controlling) dari material dengan segala bentuknya [7].

IDEAS Framework adalah metode yang berisikan langkah-langkah dari awal sampai akhir bagaimana mengidentifikasi masalah antara pekerja dengan lingkungan kerjanya lalu dibuat pemecahan masalahnya. Metode IDEAS pada umumnya diterapkan untuk mengetahui keluhan Musculoskeletal Disorders (MSDs) dan risiko ergonomik yang terjadi akibat fasilitas kerja yang kurang memadai pada pekerja selama bekerja. IDEAS Framework terdiri dari tahapan identifikasi (identify), tahapan desain (design), tahapan evaluasi (evaluate), tahapan penerapan (adapt) dan tahapan penggunaan secara keberlanjutan (sustain) [8].

Nordic Body Map merupakan kuesioner yang paling sering digunakan untuk mengetahui ketidaknyamanan pada para pekerja, yang terstandarisasi dan tersusun rapi. Tujuan dari kuesioner dari Nordic Body Map yakni untuk mengetahui bagian tubuh dari pekerja yang terasa sakit sebelum dan sesudah melakukan pekerjaan [9].

BRIEF Survey merupakan suatu alat yang digunakan untuk mengidentifikasi resiko ergonomi bagi suatu pekerjaan dengan menggunakan sistem rating untuk mengidentifikasi bahaya ergonomi yang diterima oleh pekerja dalam kegiatannya sehari-hari [10].

Tujuan penelitian ini yaitu mengevaluasi postur kerja yang tidak ergonomis berdasarkan hasil rekapitulasi BRIEF Survey dan Nordic Body Map. Hasil dari rekapitulasi jawaban pada kuisioner Nordic Body Map berupa keluhan musculoskeletal disorders (MSDs) pada bagian tubuh pekerja, sedangkan hasil dari rekapitulasi jawaban pada kuisioner BRIEF survey adalah berupa risk rating score, dimana skor ini lah yang menentukan kategori risiko (low, medium, and high) pada anggota tubuh (siku, punggung, bahu, pergelangan tangan, kaki, dan leher) pekerja pabrik tahu berdasarkan postur kerja, beban kerja, durasi kerja dan frekuensi kerja.

\section{METODE PENELITIAN}

Data yang dikumpulkan pada penelitian ini terbagi menjadi dua yaitu data primer yang berupa data profil usaha pabrik tahu, proses pembuatan tahu, keluhan penyakit akibat 
kerja, dan data postur kerja tidak ergonomis pada stasiun kerja penyaringan bubur kedelai dan penggorengan tahu. Data sekunder terdiri dari jurnal atau literatur dan buku tentang postur kerja. Data tersebut kemudian diolah melalui beberapa tahapan yaitu tahapan identify yang dilakukan dengan mengidentifikasi keluhan MSDs menggunakan Nordic Body Map dan postur kerja tidak ergonomis, selanjutnya tahapan design yaitu melakukan desain virtual human dan virtual environment menggunakan software CATIA V5. Tahap evaluasi (evaluate) dilakukan dengan menggunakan BRIEF Survey terhadap postur kerja pekerja di stasiun kerja penyaringan bubur kedelai dan stasiun kerja penggorengan tahu, sehingga nantinya diketahui skor tingkat risiko dari postur kerja tiap pekerja pabrik. Selanjutnya diberikan rekomendasi perbaikan pada Pabrik Tahu Pak Kasimin yang dapat diterapkan secara berkelanjutan (Adapt and Sustain). Hasil dari pengolahan data tersebut berupa skor rata-rata postur kerja pada stasiun kerja penyaringan bubur kedelai dan penggorengan tahu selain itu pada penelitian ini akan diberikan rekomendasi perbaikan yang diusulkan oleh peneliti.

Pada Gambar 1 dapat dilihat tahapan-tahapan yang dilakukan dalam melakukan penelitian ini.

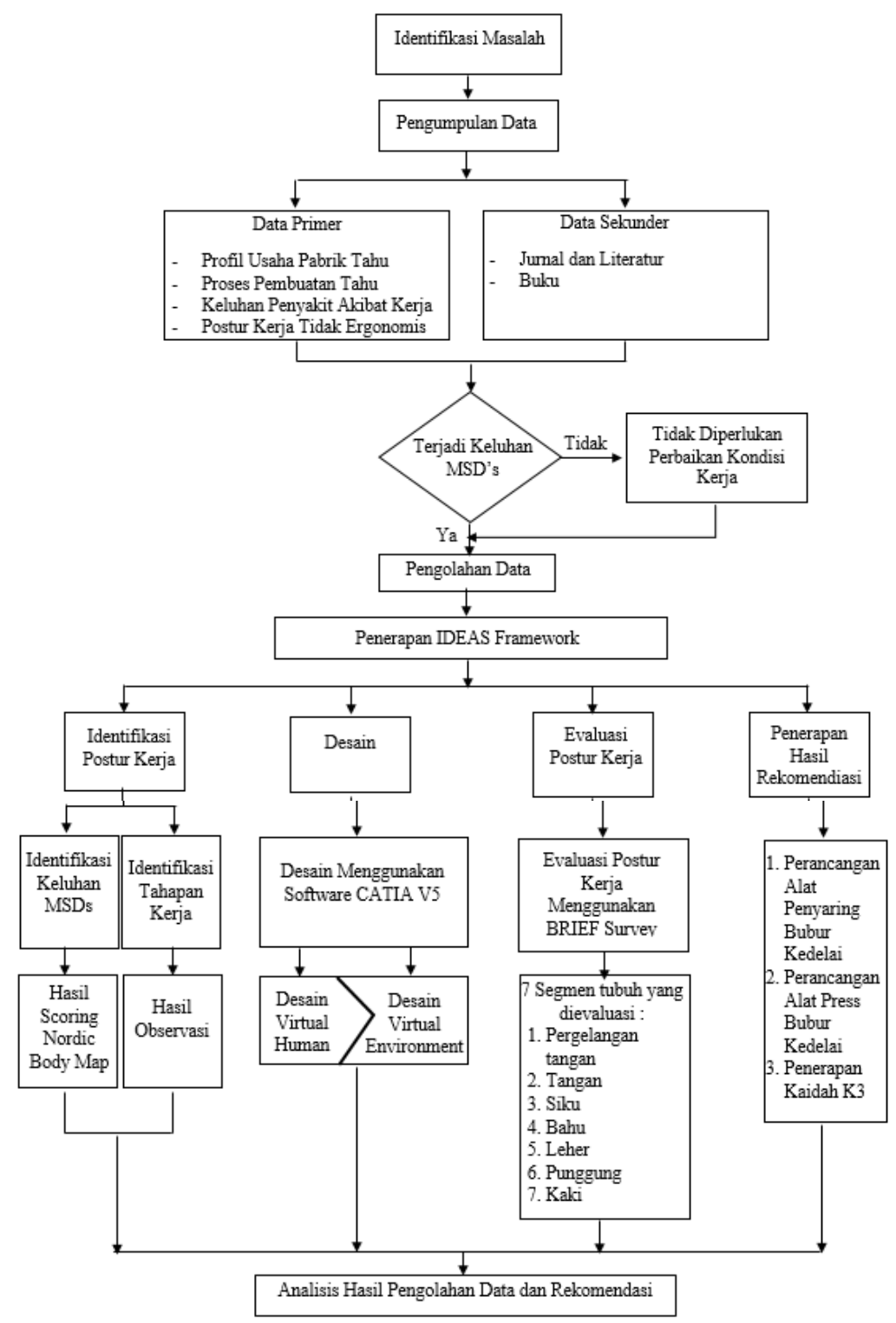

Gambar 1. Tahapan Penelitian 


\section{HASIL DAN PEMBAHASAN \\ Identify (Identifikasi)}

Pada penelitian ini, dilakukan pengolahan data terhadap 3 pekerja pabrik tahu untuk mengetahui skor individu keluhan musculoskeletal disorders dari tiap orangnya. Hasil rekapitulasi perhitungan skor individu pekerja pada pabrik tahu ditunjukkan pada Tabel 1.

Tabel 1. Skor Individu Pekerja

\begin{tabular}{cc}
\hline Pekerja & Skor \\
\hline Sandi & 59 \\
Alfin & 56 \\
Fahmi & 33 \\
\hline
\end{tabular}

Pekerja bernama Sandi memiliki skor sebesar 59 (risiko sedang) yang berarti mungkin diperlukan tindakan perbaikan di kemudian hari, pekerja bernama Alfin memiliki skor sebesar 56 (risiko sedang) yang berarti mungkin diperlukan tindakan perbaikan di kemudian hari, dan pekerja bernama Fahmi memiliki skor sebesar 33 (risiko rendah) yang berarti belum diperlukan tindakan perbaikan.

Selain dilakukan identifikasi terhadap keluhan MSDs yang dirasakan pekerja, dilakukan juga identifikasi terhadap postur kerja dari tiap stasiun kerja yang dapat dilihat pada Tabel 2.

Tabel 2. Identifikasi Postur Kerja Tidak Ergonomis

\begin{tabular}{|c|c|c|c|}
\hline No & Stasiun Kerja & Dokumentasi & Postur Kerja \\
\hline 1 & $\begin{array}{l}\text { Penyaringan } \\
\text { Bubur Kedelai }\end{array}$ & & $\begin{array}{l}\text { Pada tahap penyaringan bubur } \\
\text { kedelai pekerja melakukan } \\
\text { gerakan mengayun alat penyaring } \\
\text { bubur kedelai dengan kondisi bahu } \\
\text { terangkat, kepala pekerja } \\
\text { menunduk dan leher dari pekerja } \\
\text { miring kearah kiri hal ini } \\
\text { dikarenakan pekerja ingin } \\
\text { mengawasi kondisi bubur kedelai } \\
\text { selagi dilakukan proses } \\
\text { penyaringan }\end{array}$ \\
\hline 2 & $\begin{array}{c}\text { Penggorengan } \\
\text { Tahu }\end{array}$ & & $\begin{array}{l}\text { Pada tahap penggorengan tahu, } \\
\text { pekerja pada stasiun kerja ini perlu } \\
\text { memastikan posisi kayu bakar agar } \\
\text { tetap menghasilkan api yang besar } \\
\text { untuk dapat menghidupkan } \\
\text { kompor, sehingga kerap kali } \\
\text { pekerja selalu melakukan postur } \\
\text { kerja membungkuk untuk } \\
\text { mengatur posisi kayu bakar } \\
\text { tersebut. }\end{array}$ \\
\hline
\end{tabular}

\section{Design (Membuat Desain)}

Tahap ini dilakukan perancangan desain virtual human dan virtual environment dari kondisi aktual pada Pabrik Tahu Pak Kasimin menggunakan software CATIA V5 pada stasiun kerja penyaringan bubur kedelai dan stasiun kerja penggorengan tahu. Stasiun kerja penyaringan bubur kedelai yang ditempati oleh pekerja bernama Sandi dan Alfin terdiri dari 6 fasilitas kerja yaitu alat pengayun, kain mori, drum, wadah (ember), gayung dan ember penampung bubur kedelai yang ditunjukkan pada Gambar 2. 


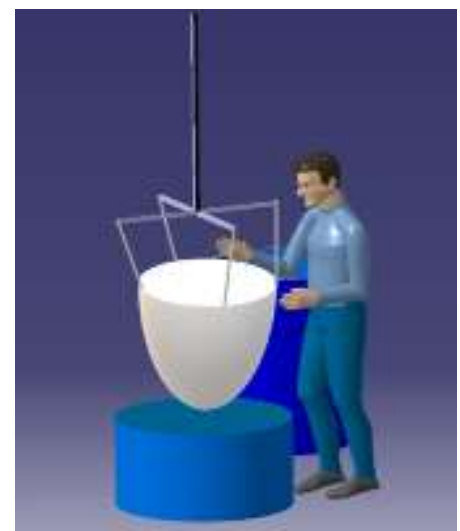

Gambar 2. Stasiun Kerja Penyaringan Bubur Kedelai

Stasiun kerja penggorengan tahu yang ditempati oleh pekerja bernama Fahmi terdiri dari 2 fasilitas kerja yaitu kompor dan alat pengangkat tahu yang ditunjukkan pada Gambar 3.

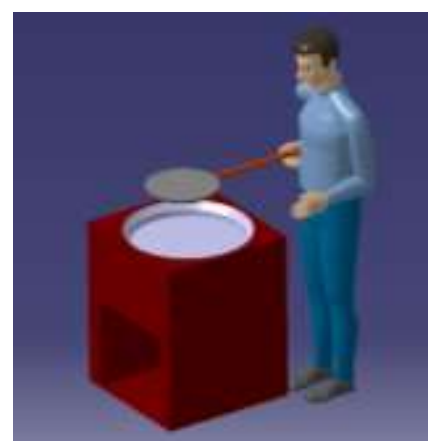

Gambar 3. Stasiun Kerja Pencetakan Tahu

\section{Evaluate (Mengevaluasi Postur Kerja Tidak Ergonomis)}

Pada tahap ini dilakukan evaluasi terhadap postur kerja dari pekerja yang berada pada stasiun kerja penyaringan bubur kedelai dan penggorengan tahu. Evaluasi postur kerja dilakukan dengan menggunakan BRIEF Survey. Metode BRIEF Survey terdiri dari beberapa penilaian yang dapat dilihat pada Tabel 3 .

Tabel 3. Penilaian BRIEF Survey

\begin{tabular}{|c|c|c|c|}
\hline Kategori & Bagian Anggota Tubuh & Nilai & Keterangan \\
\hline \multirow{8}{*}{ Beban } & \multirow{2}{*}{ Tangan dan pergelangan tangan } & 0 & Pinch grip $<0,9 \mathrm{~kg}$ atau power grip $<4,5 \mathrm{~kg}$ \\
\hline & & 1 & Pinch grip $\geq 0,9 \mathrm{~kg}$ atau power grip $\geq 4,5 \mathrm{~kg}$ \\
\hline & \multirow{2}{*}{ Siku, bahu dan kaki } & 0 & Beban $<4,5 \mathrm{~kg}$ \\
\hline & & 1 & Beban $\geq 4,5 \mathrm{~kg}$ \\
\hline & \multirow{2}{*}{ Leher } & 0 & Tidak terdapat tambahan beban \\
\hline & & 1 & Terdapat tambahan beban \\
\hline & \multirow{2}{*}{ Punggung } & 0 & Beban $<9 \mathrm{~kg}$ \\
\hline & & 1 & Beban $\geq 9 \mathrm{~kg}$ \\
\hline \multirow{4}{*}{ Durasi } & \multirow{2}{*}{$\begin{array}{c}\text { Tangan dan pergelangan tangan, siku, } \\
\text { bahu, leher serta punggung }\end{array}$} & 0 & $<10$ detik \\
\hline & & 1 & $\geq 10$ detik \\
\hline & \multirow{2}{*}{ Kaki } & 0 & $<30 \%$ per hari \\
\hline & & 1 & $\geq 30 \%$ per hari \\
\hline \multirow{4}{*}{ Frekuensi } & \multirow{2}{*}{ Tangan dan pergelangan tangan } & 0 & $<30$ kali per menit \\
\hline & & 1 & $\geq 30$ kali per menit \\
\hline & \multirow{2}{*}{ Siku, bahu, leher, punggung dan kaki } & 0 & $<2$ kali per menit \\
\hline & & 1 & $\geq 2$ kali per menit \\
\hline
\end{tabular}


Evaluasi stasiun kerja penyaringan bubur kedelai dilakukan dengan membagi aktivitas-aktivitas yang ada pada stasiun kerja tersebut menjadi 2 aktivitas utama yaitu aktivitas penuangan air dan aktivitas penyaringan bubur kedelai. Hasil evaluasi aktivitas penuangan air menggunakan BRIEF Survey dapat dilihat pada Gambar 4.
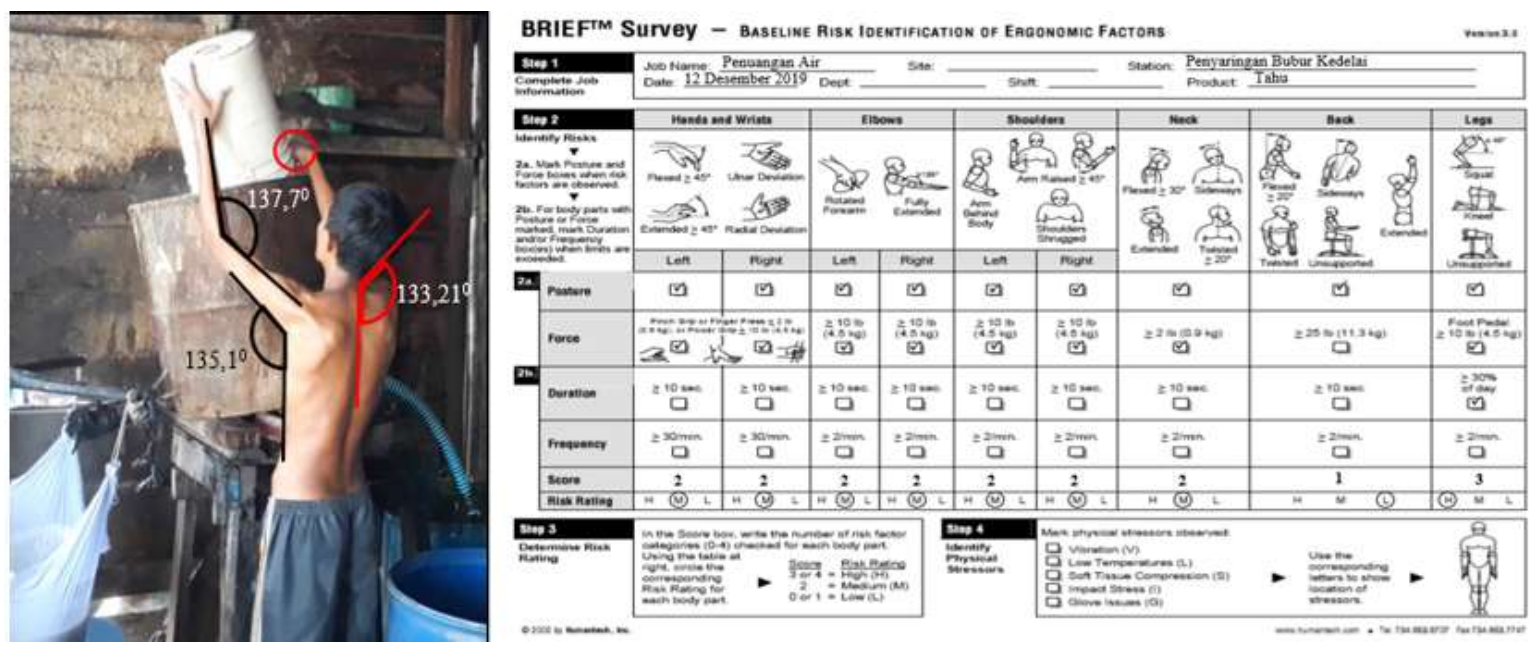

Gambar 4. Aktivitas Penuangan Air

Berdasarkan hasil evaluasi menggunakan BRIEF Survey, diketahui skor rata-rata tingkat risiko dari postur kerja tersebut adalah 2 (risiko sedang).

Hasil evaluasi aktivitas penyaringan bubur kedelai menggunakan BRIEF Survey dapat dilihat pada Gambar 5.
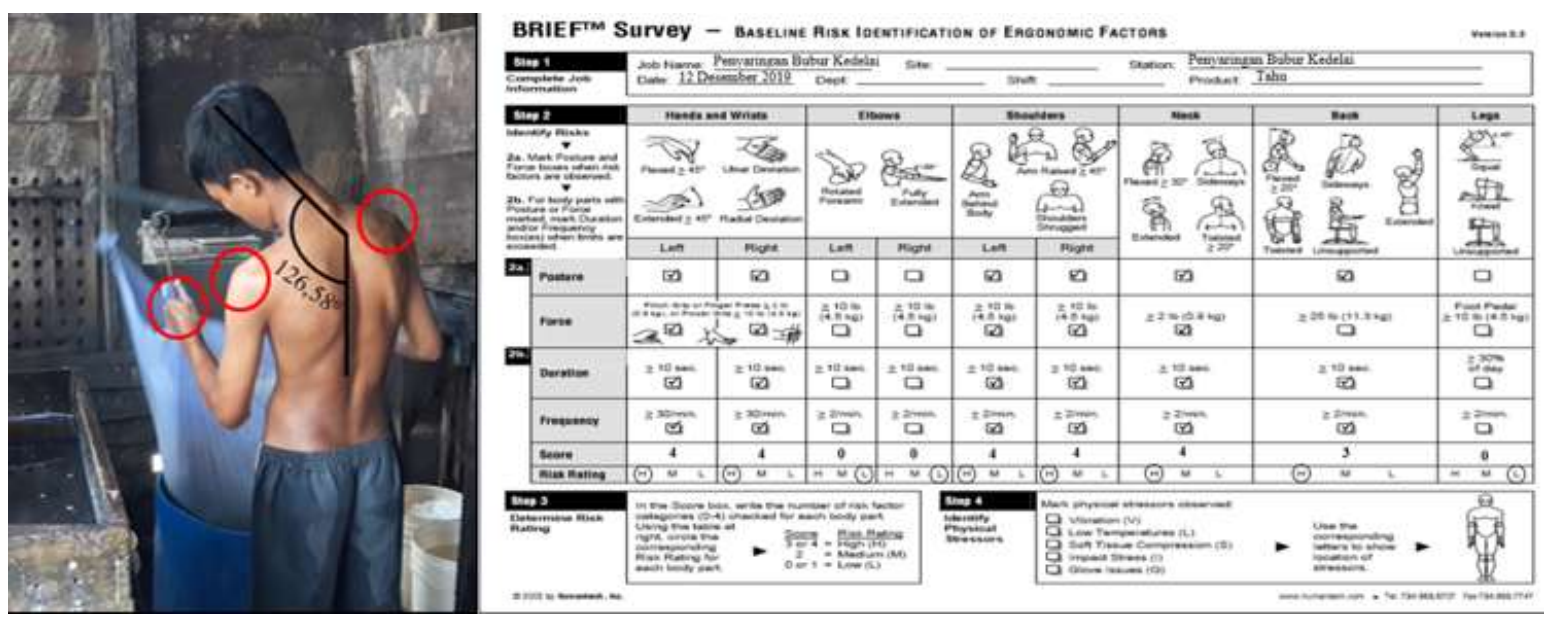

Gambar 5. Aktivitas Penyaringan Bubur Kedelai

Berdasarkan hasil evaluasi menggunakan BRIEF Survey, diketahui skor rata-rata tingkat risiko dari postur kerja tersebut adalah 3 (risiko tinggi) dan perlu dilakukan perbaikan.

Evaluasi stasiun kerja penggorengan tahu dilakukan dengan membagi aktivitasaktivitas yang ada pada stasiun kerja tersebut menjadi 2 aktivitas utama yaitu aktivitas penyusunan kayu bakar dan aktivitas penggorengan tahu. Hasil evaluasi aktivitas penuangan air menggunakan BRIEF Survey dapat dilihat pada Gambar 6. 

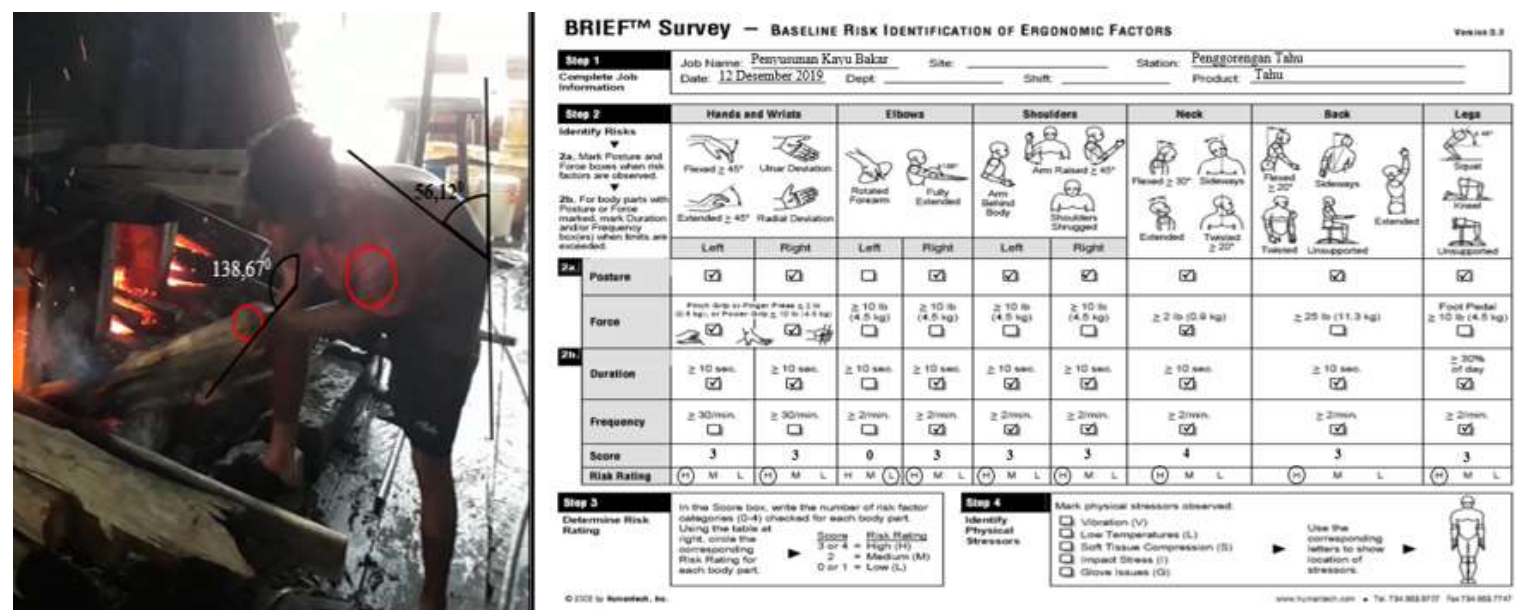

Gambar 6. Aktivitas Penyusunan Kayu Bakar

Berdasarkan hasil evaluasi menggunakan BRIEF Survey, diketahui skor rata-rata tingkat risiko dari postur kerja tersebut adalah 3 (risiko tinggi) dan perlu dilakukan perbaikan.

Hasil evaluasi aktivitas penggorengan tahu menggunakan BRIEF Survey dapat dilihat pada Gambar 7.
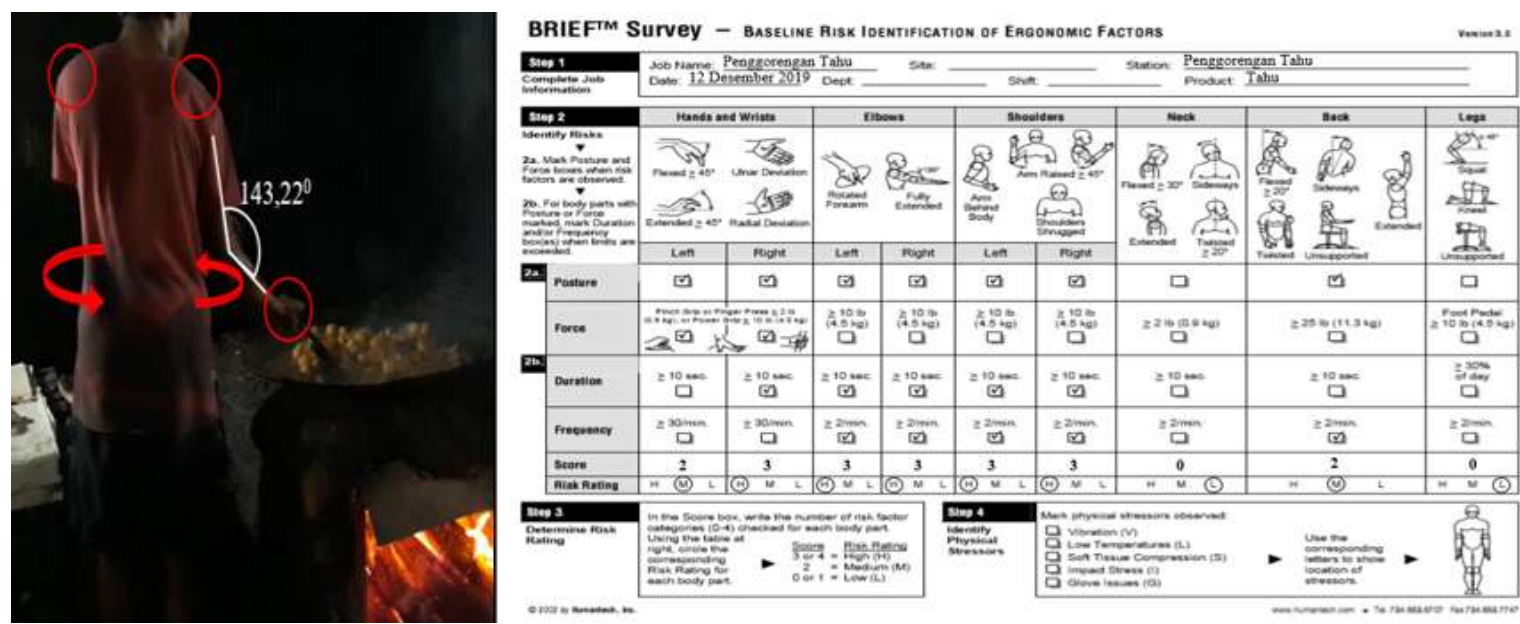

Gambar 7. Aktivitas Penggorengan Tahu

Berdasarkan hasil evaluasi menggunakan BRIEF Survey, diketahui skor rata-rata tingkat risiko dari postur kerja tersebut adalah 2 (risiko sedang).

\section{Adapt and Sustain (Penerapan Secara Keberlanjutan)}

Pada tahap ini diberikan rekomendasi perbaikan pada postur kerja yang memiliki skor tingkat risiko 3 berdasarkan hasil evaluasi menggunakan BRIEF Survey. Postur kerja tersebut ialah pada saat penyaringan bubur kedelai dan penyusunan kayu bakar. Rekomendasi perbaikan bagi aktivitas penyaringan bubur kedelai yang diberikan oleh peneliti untuk meminimalisir postur kerja tidak ergonomis dapat dilihat pada Tabel 4. 
Tabel 4. Rekomendasi Perbaikan Aktivitas Penyaringan Bubur Kedelai

\begin{tabular}{|c|c|c|c|c|c|}
\hline \multirow{2}{*}{ Aktivitas } & \multicolumn{2}{|c|}{ Kondisi Awal } & \multirow{2}{*}{ Keluhan } & \multirow{2}{*}{ Rekomendasi } & \multirow{2}{*}{ Keterangan } \\
\hline & Kanan & Kiri & & & \\
\hline
\end{tabular}

Rekomendasi perbaikan bagi aktivitas penggorengan tahu yang diberikan oleh peneliti untuk meminimalisir postur kerja tidak ergonomis dapat dilihat pada Tabel 5.

Tabel 5. Rekomendasi Perbaikan Aktivitas Penggorengan Tahu

\begin{tabular}{|c|c|c|c|c|c|}
\hline \multirow{2}{*}{ Aktivitas } & \multicolumn{2}{|c|}{ Kondisi Awal } & \multirow{2}{*}{ Keluhan } & \multirow{2}{*}{ Rekomendasi } & \multirow{2}{*}{ Keterangan } \\
\hline & Kanan & Kiri & & & \\
\hline $\begin{array}{l}\text { Penyusunan } \\
\text { Kayu Bakar }\end{array}$ & $\begin{array}{l}\text { Tangan kanan } \\
\text { power grip, siku } \\
\text { kanan } 138,6^{0}, \text { bahu } \\
\text { kanan terangkat, } \\
\text { leher miring ke kiri } \\
\text { dengan fleksi } 6^{0}, \\
\text { punggung } \\
\text { membung-kuk } \\
\text { dengan sudut } 56,12^{0}\end{array}$ & $\begin{array}{l}\text { Tangan kiri } \\
\text { finger press, } \\
\text { bahu kiri } \\
\text { terangkat }\end{array}$ & $\begin{array}{l}\text { Keluhan sakit pada } \\
\text { punggung, pinggang, } \\
\text { siku kiri dan siku kanan }\end{array}$ & $\begin{array}{l}\text { Siku kanan dan kiri tidak } \\
\text { ditekuk } \geq 135^{\circ}, \text { bahu kanan } \\
\text { tidak terangkat, leher tegak } \\
\text { lurus terhadap objek dan } \\
\text { punggung membungkuk < } \\
20^{\circ}\end{array}$ & $\begin{array}{l}\text { Mengadakan pelatihan } \\
\text { bagi pekerja cara } \\
\text { melakukan pengangkatan } \\
\text { beban yang ergonomis } \\
\text { dan melakukan } \\
\text { pengendalian } \\
\text { administratif } \\
\text { menggunakan kaidah } \\
\text { K3, seperti melakukan } \\
\text { rotasi kerja }\end{array}$ \\
\hline
\end{tabular}

\section{KESIMPULAN}

Pada Pabrik Tahu Pak Kasimin, terdapat postur kerja yang tidak ergonomis pada stasiun kerja penyaringan bubur kedelai dengan postur kerja membungkuk dan kondisi leher yang miring dengan sudut $126,58^{\circ}$, dan stasiun kerja penggorengan tahu dengan postur kerja membungkuk sebesar $56,12^{0}$. Pada stasiun kerja tersebut terdapat 2 aktivitas kerja dengan postur kerja risiko tinggi yaitu pada proses penyaringan bubur kedelai dan penyusunan kayu bakar dengan skor 3. Usulan perbaikan pada stasiun kerja yang dilakukan peneliti yaitu pembuatan alat penyaring bubur kedelai dan alat press bubur kedelai yang memiliki mekanisme kerja alat tersebut berbeda pada saat proses penyaringan bubur kedelai di Pabrik Tahu Pak Kasimin saat ini. Alat usulan yang direkomendasikan oleh peneliti menggunakan sistem engkol untuk mengurangi postur kerja yang tidak ergonomis pada pekerja. Pada stasiun kerja penggorengan tahu, diberikan rekomendasi perbaikan berupa penerapan cara melakukan pengangkatan beban yang ergonomis sesuai kaidah K3 dan penerapan pengendalian administratif yaitu melakukan rotasi kerja untuk mengurangi durasi pengangkatan beban secara terus-menerus.

\section{DAFTAR PUSTAKA}

[1] A. Anjanny, A. Ferusgel, dan D. M. S. Siregar. 2019. Keluhan Musculoskeletal Disorders (MSDs) Pada Pekerjaan Penggunaan Komputer di Badan Pusat Statistik Provinsi Sumatera Utara. J. Kesehat. Glob., vol. 2, no.1, hal. 45-51,

[2] L. D. Fathimmahayati, M. R. Wardana, dan N. A. Gumilar, 2019. Analisis Risiko K3 dengan Metode HIRARC pada Industri Tahu dan Tempe Kelurahan Selili, Samarinda. J. Rekayasa dan Inov. Tek. Ind., vol.7, no.1

[3] W. S. Kuswana, 2014. Ergonomi dan K3 Kesehatan dan Keselamatan Kerja. Bandung: PT. Remaja Rosdakarya.

[4] M. Mengoni, M. Matteucci, dan D. Raponi. 2017. A Multipath Methodology to Link Ergonomics, Safety and Efficiency in Factories, Procedia Manuf., vol. 11, hal. 1311- 
1318

[5] M. H. Salih, 2017. A Literature Review of Ergonomics Programs. Proceedings of $3^{\text {rd }}$ Int. Eng. Conf. Dev. Civ. Comput. Eng. Appl., Feb 26-27, hal. 191-202.

[6] P. Wahyudi dan W. Hariyono, 2017. Kesesuaian Manual Assessement Chart Tool dan NIOSH Lifting Equation Dalam Identifikasi Keluhan Muskuloskeletal Pekerja Industri. BKM J. Community Med. Public Heal., vol. 33, no.8, hal. 377-382.

[7] M. N. Affa dan B. I. Putra, 2017. Analisis Manual Material Handling Pada Pekerja Borongan Di PT. JC dengan Metode NBM dan RWL. Prozima, vol.1, no.1, hal. 2232.

[8] D. F. Pringgabaya dan H. Prastawa, 2017. Perancangan Fasilitas Kerja Ergonomis Dengan Menggunakan Metode IDEAS. Ind. Eng. Online J., vol.6, no.1, hal. 1-6.

[9] D. A. Anggraini dan N. C. Bati, 2016. Analisa Postur Kerja Dengan Nordic Body Map \& Reba Pada Teknisi Painting Di PT. Jakarta Teknologi Utama Motor Pekanbaru. J. Phot., vol.7, no.1

[10] B. Adiguna, H. Adam, dan C. D. Kusmindari. Perbaikan Stasiun Kerja Kritis Menggunakan Metode Ergonomic Assesment Survey (EASY). Semin. Nas. Glob. Compet. Advant., hal. 1-9, 2016. 